\title{
PARÁMETROS ANTROPOMÉTRICOS DE CRECIMIENTO EN UN GRUPO INDIGENA MAYANCE (TOJOLABAL)
}

\author{
Julieta ArÉchiga \\ y Carlos Serrano \\ Instituto de Investigaciones \\ Antropológicas, UNAM
}

\section{Introducción}

El crecimiento físico infantil es un proceso que se expresa a través del tamaño y masa corporal; depende tanto de la base genética del grupo humano del cual se trate como de los factores ambientales en que éste se desarrolla.

La valoración del crecimiento se puede realizar mediante el examen de las variables antropométricas que afectan diferencialmente, por sus características de herencia y ambiente, los subgrupos de una población. La influencia negativa de los factores ambientales puede ser detectada, así, en aquéllos que no han contado con los recursos económicos indispensables para el desenvolvimiento óptimo de su potencial hereditario y que, durante siglos, se han alimentado defectuosamente.

Es indudable que las magnitudes físicas del cuerpo están influidas por la nutrición, en la cual se conjugan una serie de factores mesoambientales, tanto del orden cultural como socioeconómico. Por consiguiente, determinados datos antropométricos pueden proporcionar valiosa información sobre los problemas de subnutrición que afectan a las dimensiones y a la composición general del cuerpo, en sectores de población que viven en condiciones de vida desfavorables.

En la población mexicana, biológicamente muy heterogénea y con fuertes contrastes sociales y culturales, este tipo de problemas se han estudiado principalmente en el ámbito urbano con referencia a los estratos sociales que allí se conforman notoriamente; en cambio, e] sector rural de la población, principalmente el de ascendencia indí. 
gena, ha sido mucho menos atendido. En estos grupos de tradición cultural autóctona se debe considerar no sólo su particular composi. ción genética sino sus adversas condiciones de vida que se manifiestan, con frecuencia, en extrema depauperación biológica y social.

Nuestro trabajo examina una muestra de población tojolabal, grupo del sector rural mexicano, clasificado como indígena, que vive en pre. carias condiciones socioeconómicas y en consecuencia, con severas li. mitaciones de acceso a una salud ${ }^{1}$ y nutrición ${ }^{2}$ adecuadas. Esta situa. ción se refleja por una acusada mortalidad infantil en el grupo, en infantes cuya edad era de 1 a 4 años, alcanzando un porcentaje de $23.4 \%$ durante la última década.

La investigación planteada se propone examinar los efectos que la alimentación y sus factores condicionantes ejercen sobre el desarrollo de la población infantil tojolabal. Por el momento en esta ocasión abordamos sólo y de manera preliminar, el estudio de algunos de los datos antropométricos obtenidos; posteriormente habrá de analizarse el resto de los materiales y datos referentes a la encuesta nutricional, así como el examen clínico que se practicó en este grupo.

\section{Algunos datos sobre los tojolabales}

Entre los grupos mayances que subsisten en la actualidad el tojola. bal destaca como uno de los menos estudiados.

$\mathrm{Su}$ habitat actual se localiza principalmente en el Municipio de Las Màrgaritas (con una superficie de $4500 \mathrm{~km}^{2}$ ) y en menor escala en los municipios de Altamirano, Comitán e Independencia, todos en el Estado de Chiapas (Fig. 1).

Dado que su cultura no ha sido exhuberante, las fuentes históricas, hasta donde se sabe, no precisan el origen y situación de los tojolabales ni en el tiempo ni en el espacio, resultando igualmente difícil, por esta razón, su identificación arqueológica.

1 Según los datos proporcionados por el médico Mario H. Ruz, que realizó el estudio clínico, se detectaron:

a) Alta frecuencia de uncinariasis (Necatus americanus), $47 \%$ aproximadamente; como es sabido, este parásito provoca anemia severa y trastornos en el crecimiento.

b) Alto porcentaje de despigmentación difusa central en la cara; dato que señala Jelliffe (1968) como sugestivo de malnutrición calórico-proteica, así como la palidez conjuntival, que clínicamente es coincidente con una anemia importante.

2 Entre las características de la dieta se cuentan el consumo de maíz, frijol, calabaza y chile como alimentos básicos y una precaria ingestión de proteína animal. 
Los datos históricos son muy escasos, no existe referencia al grupo durante los siglos xvi y xvIr, mencionándose por primera vez la len. gua chañabal (tojolabal) hasta 1735. Posiblemente los tojolabales son pobladores relativamente recientes de la zona que hoy ocupan; según Ruz (en prensa) el primitivo asentamiento del grupo tojolabal estaría localizado en los Altos de Guatemala, en un área cercana a la que hoy habitan los Chuj, emigrando posteriormente hasta el habitat actual. Es posible que el grupo haya permanecido inicialmente en las zonas selváticas o montañosas cercanas y clasificado dentro de términos ambiguos como "choles" o "lacandones", y que se viera finalmente obligado por el avance conquistador, el celo misionero, el empuje de otros grupos cercanos, a descender paulatinamente hasta el somontano.

Según datos del mismo autor, el asentamiento de Las Margaritas se inicia a fines del siglo xvIr como concesión de la Corona Española a pobladores del cercano Comitán. Para 1885, el cura del lugar informa que la parroquia de Margaritas posee dos pueblos: Margaritas, con 400 ladinos y 870 indígenas, y San Fermín (hoy Independencia), con 500 habitantes todos indígenas. Además se refiere a 3821 indígenas distribuidos en 46 fincas.

En la actualidad, los hablantes de tojolabal llegan aproximadamente a 32000 . Existen divergencias dialectales entre las diversas comunidades; sin embargo, el lenguaje ocupa un lugar primordial entre los elementos internos que preservan la identidad tojolabal; pero también son factores importantes la participación en tradiciones, los patrones conductuales y mitos comunes, además de una fuerte identificación local — ciertamente más comunal que tribal— que se plasma en el sentimiento de grupo, conciencia étnica y ayuda mutua (M. H. Ruz, en prensa, b).

A partir de 1936, con la Reforma Agraria, algunos grupos de tojolabales lograron dotación de tierras, independizándose así de las fincas y formando sus ejidos.

El cultivo principal es el maíz; en muy pequeña escala e irregularmente cultivan frijol, calabaza, chile y chayote; también poseen árboles frutales como naranja, lima y níspero. Eventualmente crían animales domésticos: cerdos, gallinas, guajolotes, ganado vacuno y algunos caballos, cabras, ovejas y burros. Todos estos animales, cuando se tienen, están visiblemente mal alimentados. La cantidad total de animales existentes en la comunidad es muy escasa, y tienen un papel marginal en la economía familiar, ya que la venta de ganado es una reciente innovación en la economía indígena (Guerrero, 1974).

La recolección y la caza se practican en pequeña escala. Práctica- 
mente toda la producción se destina a satisfacer las necesidades inmediatas de la familia, por lo que podría decirse que se trata de una producción de autoconsumo.

\section{Material y método}

La muestra estudiada corresponde a escolares de ambos sexos, entre los 6 y 15 años. El total de individuos es de 554, de los cuales 287 son varones y 267 niñas. Las mediciones antropométricas fueron realizadas durante tres temporadas de campo en la zona tojolabal, a partir de 1976, en el marco del programa de investigaciones de Antropología Física del Centro de Estudios Mayas.

Las comunidades visitadas se encuentran todas en el municipio de Las Margaritas: Allende, Venecia, Morelia, La Soledad (Ejido Chiapas), Tabasco, Leyva Velázquez, Rafael Ramírez, Saltillo, Veracruz, Bajacú, Jalisco, Fco. I. Madero (ver mapa). Las condiciones de vida no varían mayormente entre ellas, si bien la implantación de algunos albergues infantiles, dependientes del Instituto Nacional Indigenista, puede introducir algunos cambios en la dieta aunque el número de escolares a los que alcanza es más bien reducido.

Las dificultades con que se tropieza en un estudio sobre crecimiento infantil en comunidades indígenas son numerosas. Quizá la principal sea la ignorancia de la edad exacta de los sujetos a examinar. Aunque a últimas fechas se ha incrementado la conciencia del registro legal de los nacimientos, fueron muchos los casos en que no se acudió a cumplir con tal disposición, o la boleta expedida por el Registro Civil había sido extraviada, o maltratada hasta hacer ilegibles los datos asen. tados. El rito bautismal, que se cumple con más frecuencia, y del cual debiera haber la constancia eclesiástica respectiva no mejoró tampoco la información que precisábamos para el estudio, en parte porque los nombres de niños registrados eclesiásticamente no concuerdan con los de aquellos infantes de quienes se tomó la muestra, inclusive, mu. chos de los niños registrados no aparecen. De tal manera, un alto porcentaje de los escolares contactados no pudieron ser integrados a las series de estudios, quedando éstas constituidas sólo por aquéllos que certificaron su fecha de nacimiento.

Los datos antropométricos recabados incluyen estatura total, dimen. siones de segmentos corporales (cabeza, tronco, extremidades), pliegues cutáneos y peso. Para esta presentación preliminar hemos elegido las siguientes, que permiten ya una apreciación del problema planteado: estatura total, peso, estatura sentado, perímetro cefálico, perí- 
metro del brazo y pliegue cutáneo tricipital. En base a las dos últimas medidas se elaboró la circunferencia muscular del brazo, según la fórmula establecida por Jelliffe (1968), $\mathrm{C}_{2}=\mathrm{C}_{1}-\pi \mathrm{S}_{\mathrm{t}}$, en donde $\mathrm{C}_{1}$ es el perímetro braquial, $\mathrm{S}_{\mathrm{t}}$ representa el pliegue cutáneo y $\mathrm{C}_{2}$ el perímetro muscular. Según este autor (1968) "El músculo y la grasa son los tejidos blandos que más varían con la deficiencia de proteínas y calorías. La antropometría tisular puede aplicarse a esos dos tejidos al evaluar el estado de nutrición de una comunidad". Para este efecto, recomienda la medición del pliegue cutáneo tricipital como una de las más prácticas para calcular las reservas calóricas.

Cada una de las medidas se tomó según las técnicas estandarizadas de aceptación general. Los instrumentos utilizados fueron: un antro. pómetro de Martin, una báscula Secca, una cinta métrica metálica y un calibrador de pliegue cutáneo Harpenden.

Efectuamos la comparación del grupo tojolabal con otros grupos, tanto de población rural ${ }^{3}$ como urbana $;{ }^{4}$ para observar las diferencias en el crecimiento y tener la posibilidad de cuantificarlas sin olvidar en ningún momento su heterogeneidad genética, geográfica, cultural y socioeconómica. Para ello se efectuó la superposición de las curvas de distribución de valores correspondientes a los distintos grupos.

En el procesamiento de los datos ${ }^{5}$ se incluyó el cálculo de la media aritmética y la desviación estándar, así como los errores estándar respectivos.

\section{Resultados}

\section{a) Estatura}

En el cuadro 1 se presentan los valores estadísticos para esta medida.

Nuestras series tojolabales, en ambos sexos y en todas las edades, muestran una talla pequeña (Figs. 1 y 2 ). Haciendo un análisis de los grupos rurales únicamente, vemos que en los grupos de 6,8 y 13 años en varones y de 6 años en niñas, los tojolabales y los zapotecos tienen valores similares, apartándose la muestra cholulteca de ambas; en las series femeninas nuestro grupo de estudio se sitúa muy por

3 Los grupos rurales estudiados son: Zapotecos estudiados por Malina, Cholultecas estudiados por López y Ramos, y Tojolabales del presente estudio.

4 Los grupos urbanos: clase media de la Ciudad de México, estudiados por Ramos Galván.

5 Para la computación y procesamiento de los datos antropométricos, se contó con la asesoría del físico Víctor Mantilla C. 
debajo de los valores correspondientes a todas las demás series (con excepción del grupo de 6 años ya señalado).

Es notable la gran diferencia que se establece entre los datos estaturales de los tojolabales, que entre las muestras rurales, presenta las cifras más bajas, y las series urbanas, cuyos valores alcanzan hasta 10 cm más, tendiendo a incrementarse esta diferencia en los grupos de edad mayores. Este fenómeno se constata en ambos sexos.

\section{b) Peso (cuadro 2)}

Los valores promedio para el peso, en las muestras infantiles tojolabales de ambos sexos son, en general, menores a los de las series comparadas (Figs. 3 y 4). Se aproximan más a los valores de las muestras rurales, quedando separados notablemente de los grupos urbanos, con diferencias que tienden a incrementarse en los grupos de edad más avanzados.

\section{c) Estatura sentado (cuadro 3)}

En este parámetro contamos únicamente, como referencia para la comparación de nuestros datos, con las dos muestras urbanas ya citadas; como era de esperarse la curva de los tojolabales queda en la parte inferoir de las gráficas, muy distante de las muestras citadinas. La observación es válida para ambos sexos (Figs. 5 y 6 ).

\section{d) Parámetro cefálico (cuadro 4)}

No se consideró en los grupos rurales con que hemos venido reali. zando la comparación de nuestros resultados. Respecto a las muestras urbanas, la distribución de valores del perímetro cefálico de los tojolabales describe una curva muy por abajo de la de los grupos citadinos, particularmente en el sexo masculino (Figs. 7 y 8 ).

\section{e) Perímetro del brazo relajado (cuadros 5 y 6 )}

Se observa mucha similitud, en las curvas del grupo tojolabal y zapo. teca de las series masculinas (Fig. 9). El otro grupo rural (cholultecas) presenta valores superiores y las muestras urbanas los más altos.

En la serie femenina, los grupos rurales muestran gran cercanía, aunque lo tojolabales describen la curva inferior (Fig. 10). Los grupos urbanos se separan netamente en la parte superior de la gráfica. 


\section{f) Pliegue cutáneo del triceps (cuadros 5 y 6 )}

Se cuenta sólo con los datos comparativos de los grupos rurales. En la serie masculina (Fig. 11), los tojolabales muestran valores muy similares a los zapotecas, separándose ambos de los valores de la muestra de Cholula.

En la serie femenina, en cambio, la curva de la muestra tojolabal queda muy por debajo de las otras dos, las cuales presentan una similitud notable (Fig. 12).

\section{g) Perímetro muscular del brazo (cuadros 5 y 6 )}

Nuevamente los datos comparativos se refieren sólo a grupos rurales. En ambos sexos, en las tres muestras consideradas, los valores son próximos (Figs. 13 y 14), sobre todo entre zapotecos y tojolabales. Estos últimos tienden, sin embargo, a presentar valores inferiores, contrastando más con la serie cholulteca, de valores más altos.

\section{Discusión}

A partir del examen antropométrico comparativo realizado, se observa que las magnitudes corporales a diferentes niveles de edad muestran divergencias notables según se trate de población urbana o rural.

Los parámetros antropométricos de los tojolabales, que hemos tratado de poner en relieve, quedan situados consistentemente por debajo de las otras series con que se les ha comparado. Se aproximan mucho a las muestras rurales y en algunos casos se identifican práctica. mente con ellas separándose en cambio, significativamente, de los grupos urbanos. ¿De qué manera inciden los factores genéticos y ambien. tales para la manifestación de este fenómeno?

Dos características antropométricas han mostrado su utilidad para sintetizar el crecimiento y el desarrollo infantil; la talla y el peso, la primera con una importante determinación genética, la segunda con mayor labilidad ambiental.

Así, en el caso de la estatura, se trata de un carácter diferencial según el acervo genético del grupo en cuestión, aunque no pueda excluirse la modificación del fenotipo por influencia del ambiente.

$\mathrm{La}$ talla baja de los tojolabales de nuestro estudio podría en efecto relacionarse con el contexto económico deficiente, así como a los efec. tos nocivos de las tradiciones, creencias y supersticiones y otros factores del ambiente social que impiden al grupo acercarse a su potencial 
genético óptimo. Sin embargo, la distribución de los valores estatura. les, aunque en plano inferior, resulta similar a la de los otros grupos de lo que se deduce un ritmo de crecimiento semejante pero de talla pequeña en todas las edades.

Por otro lado, el peso resulta muy reducido si se compara con los grupos urbanos de Faulhaber y Ramos Galván, siendo más cercano al de los grupos rurales, concordando de este modo con la talla pequeña señalada.

Tal constatación lleva a considerar que la estatura reducida de los niños tojolabales podría tener más bien una base genética y dependería en buena medida de la talla pequeña de sus progenitores, toda vez que es bien sabido que existe una alta correlación positiva entre la estatura de los padres y la de los hijos. Debe hacerse notar a este respecto que la media estatural de los progenitores masculinos tojolabales es de $156.1 \mathrm{~cm}$ (Aréchiga, 1979, p. 182), en tanto que los padres del sector urbano presentan una talla promedio de $160.8 \mathrm{~cm}$ (Faulhaber, 1976, p. 279).

En general los grupos mayances, de los cuales los tojolabales forman parte, presentan una talla pequeña cuyo condicionamiento genético podría quizá explicarse a través del mecanismo de la selección natural; ésta, bajo condiciones nutricionales limitadas, habría llevado a la eliminación de genes que favorecen un crecimiento rápido y una mayor estatura adulta, conservando los genes para un crecimiento lento y una talla adulta más baja, cuyo valor adaptativo puede resultar favorable en condiciones nutricionales precarias (Frisancho et al., 1973).

De esta manera, otros rasgos antropométricos como la talla sentados y el perímetro cefálico, resultan también menores a los de las muestras urbanas que representan a grupos mestizos, con un componente europeo apreciable. El grupo tojolabal, en cambio, corresponde a una población altamente indígena en la que, si bien se puede detectar una mezcla biológica no indígena, ésta puede considerarse reducida (Aré. chiga, 1979; Serrano, en prensa).

En cuanto al perímetro del brazo relajado y el pliegue cutáneo tri. cipital, que pueden calificarse de ecosensibles, han sido por lo mismo utilizados como indicadores de malnutrición calórico-proteica (Jelliffe, 1966, 1968, 1969). En los sujetos estudiados, el perímetro del brazo es mayor en las niñas que en los niños de los nueve años en adelante, de acuerdo a la tendencia femenina de presentar brazos más gruesos. No existe gran diferencia en esta medida entre las muestras rurales, pero si es notable entre grupos rurales y urbanos.

Por otra parte, las gráficas de las mediciones del brazo muestran 
sifras reducidas en relación a todos los demás grupos; sin embargo, no podemos valorarlas con precisión como indicadores de malnutri. ción debido a la inexistencia de normas de referencia adecuadas. A pesar de ello, si consideramos los valores de referencia de Jelliffe ya citados, tenemos en los varones que para perímetros de brazo, pliegue cutáneo del triceps y perímetro muscular, alcanzan un 85,75 y $85 \%$ de la norma respectivamente y en las hembras 85,65 y $90 \%$, lo cual señala, de todos modos, un estado nutricional deficiente que concordaría con la salud y el medio socioeconómico precarios que prevalecen en las comunidades.

En resumen, la evaluación antropométrica es útil cuando se trata de relacionar las condiciones del ambiente con el desarrollo del organismo; los estudios transversales del crecimiento permiten estimar la influencia del primero sobre el segundo, sin olvidar el sustrato genético de cada uno de los grupos de estudio.

En este trabajo, los parámetros de crecimiento obtenidos en el grupo tojolabal fueron comparados con sectores de población urbana con los cuales contrastan grandemente; estos últimos corresponden a sujetos con un intenso mestizaje que viven en condiciones socioeconómicas favorables respecto al grupo tojolabal que, por su parte, conserva marcadas características indígenas, biológicas y culturales, debido a su relativo aislamiento, sus prácticas socio-culturales y sus carencias económicas.

De los grupos del ámbito rural con los cuales se practicó la comparación antropométrica, la semejanza mayor se estableció con la muestra zapoteca, que corresponde a un grupo indígena con características semejantes a los tojolabales en cuanto a escasa mezcla biológica y condiciones sociales y culturales. En cambio el grupo de Cholula, debido a su cercanía con un importante centro urbano, al desarrollo de las comunicaciones que caracteriza al centro del país, así como el mayor acceso a fuentes de trabajo y más posibilidades de mestizaje, queda en un lugar intermedio entre los grupos urbanos y los indígenas - $\mathrm{za}$. potecos y tojolabales - , casi en todos los parámetros estudiados, aunque con mayor similitud desde luego, con los grupos indígenas.

El examen del total de datos antropométricos obtenidos en la muestra tojolabal, permitirá seguramente precisar estas aseveraciones, si bien lo ahora expuesto muestra ya un panorama más bien deplora. ble de las condiciones físicas y sociales de los habitantes indígenas del Municipio de Las Margaritas, situación que resulta tanto más grave cuando sus consecuencias se reflejan severamente en el sector infantil de la población. 


\section{BIBLIOGRAFIA}

Aréchiga, J.

1979 Algunos aspectos de la Antropología Física de los Tojolabales (Estudio comparativo). Tesis Profesional. Escuela Nacional de FAULhaber, J. Antropología e Historia. México.

1976a Investigación Longitudinal del Crecimiento. Colección Científica, Antropología Física, 26, p. 310. Instituto Nacional de Antropología e Historia, México.

1976b "El crecimiento de un grupo de niños normales de la Ciudad de México". Anales de Antropología, 13: 275-288. Instituto de Investigaciones Antropológicas. UNAM. México.

Frisancho, A. R., Pallardel D. SÁnchez y L. Yanes

1973 "Adaptative Significance of Small body Size under Poor SocioEconomic condition in Southern Peru", American Journal of Phy.

Guerrero, F. J. sical Anthropology, 39: 225-262.

1974 "Notas sobre los tojolabales de Chiapas". Boletin de Información del Centro de Estudios Mayas, 1 (1): 33-39. Instituto de JELLIFFe, E. F. Investigaciones Filológicas, UNAM, México.

1968 Evaluación del estado de Nutrición de la Comunidad. Con especial referencia a las encuestas en las regiones en desarrollo. Organización Mundial de la Salud. Monografía 53, Ginebra.

Jelliffe, E. F. y D. B. Jelliffe

1969 "The Arm Circunference as a Public Healt Index Protein Calorie Malnutrition of Early Childhood", The Journal of Tropical Pediatries, Vol. 15, No. 4: 179-188.

López Alonso, S. y R. M. Ramos

1977 "Ensayo sobre antropometría nutricional en una muestra de la población escolar de Cholula, Puebla", Anales del Instituto Na-

Malina, R. M. et. al. cional de Antropología e Historia, Vol. VI, México.

1972 "Estatura, peso y circunferencia de brazo en una muestra transversal de niños zapotecos de 6-14 años", Anales de Antropolo-

Ramos Galván, R. gía, Vol. IX: 143-155, UNAM. México.

1975 Somatometría pediátrica. Estudio semilongitudinal en niños de la ciudad de México. Archivos de Investigación Médica, 6/Sup.

Ruz, M. H. 1. Instituto Mexicano del Seguro Social, México.

(En Prensa)a "En Torno a los Orígenes", Los Legítimos Hombres. Aproximación Antropológica al Grupo Tojolabal. Vol. I. Centro de Estudios Mayas, Instituto de Investigaciones Filológicas, UNAM, México.

(En Prensa)b Los Legítimos Hombres. Aproximación Antropológica al Grupo Tojolabal. Vol. II, Centro de Estudios Mayas, Instituto de Investigaciones Filológicas, UNAM, México. 


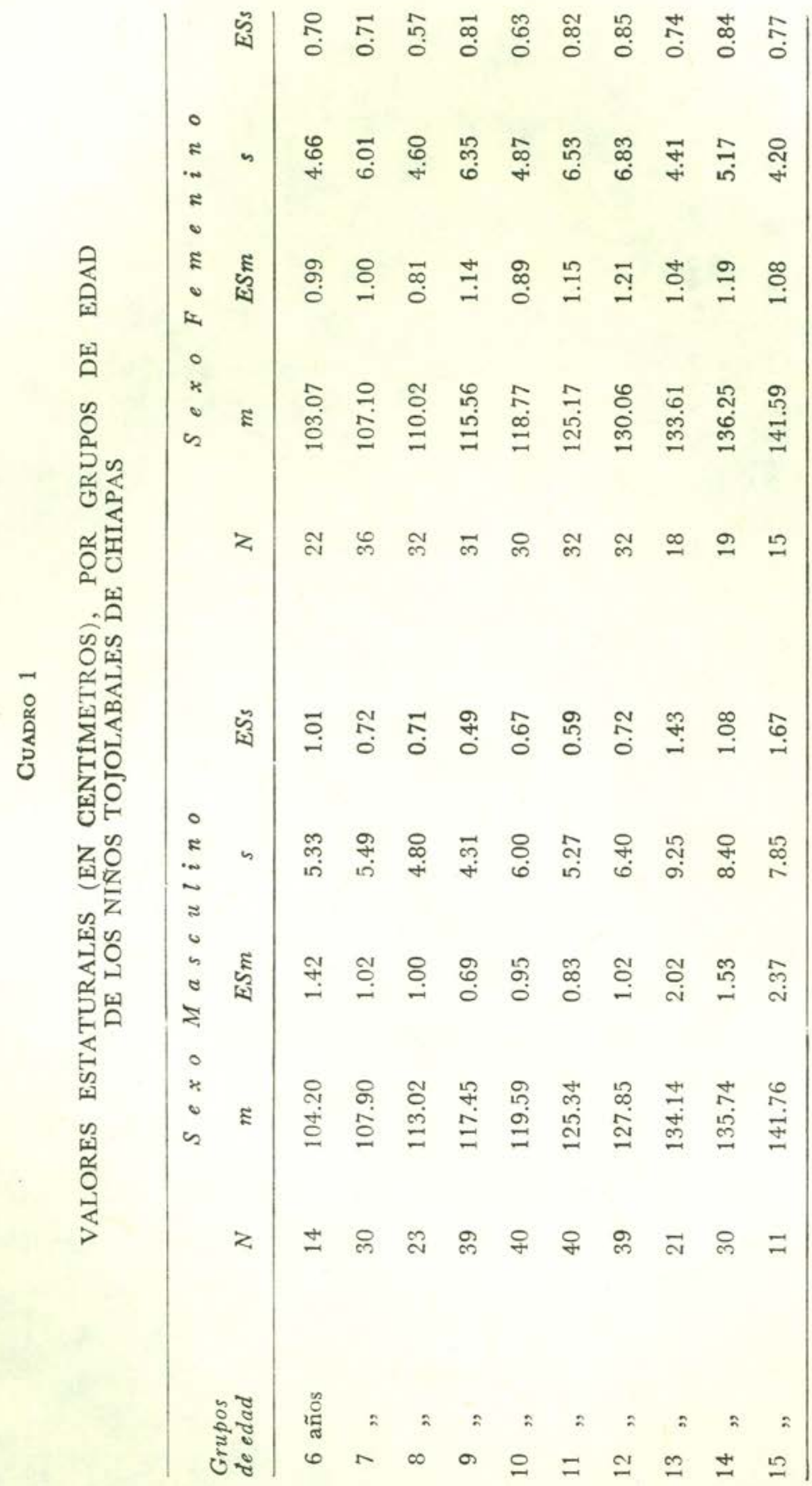

Estudios de Cultura Maya. Vol. XIII, 1981

Instituto de Investigaciones Filológicas/

Centro de Estudios Mayas, UNAM

http://www.iifilologicas.unam.mx/estculmaya/ 


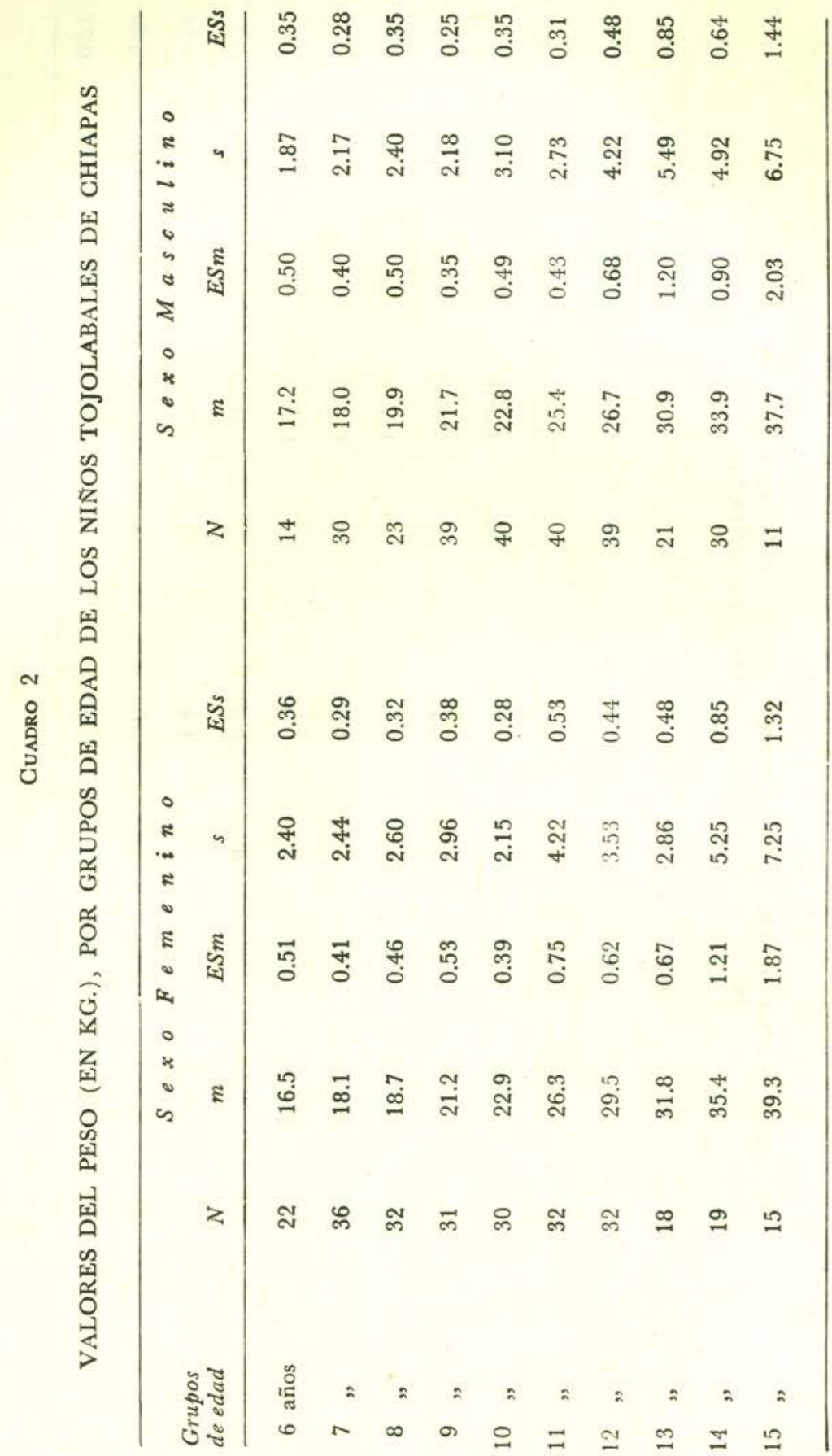

Estudios de Cultura Maya. Vol. XIII, 1981

Instituto de Investigaciones Filológicas/

Centro de Estudios Mayas, UNAM

http://www.iifilologicas.unam.mx/estculmaya/ 


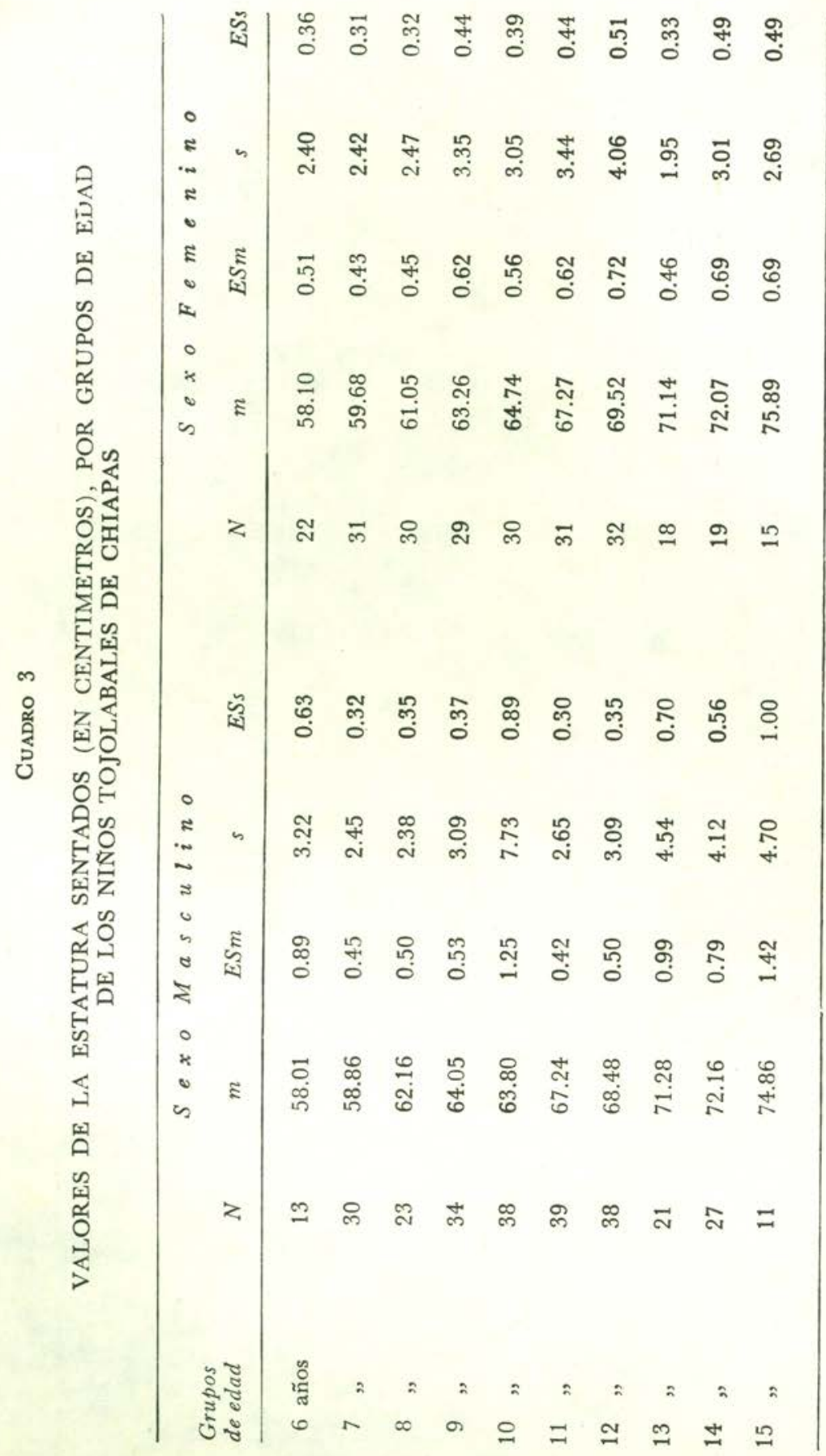

Estudios de Cultura Maya. Vol. XIII, 1981

Instituto de Investigaciones Filológicas/

Centro de Estudios Mayas, UNAM

http://www.iifilologicas.unam.mx/estculmaya/ 


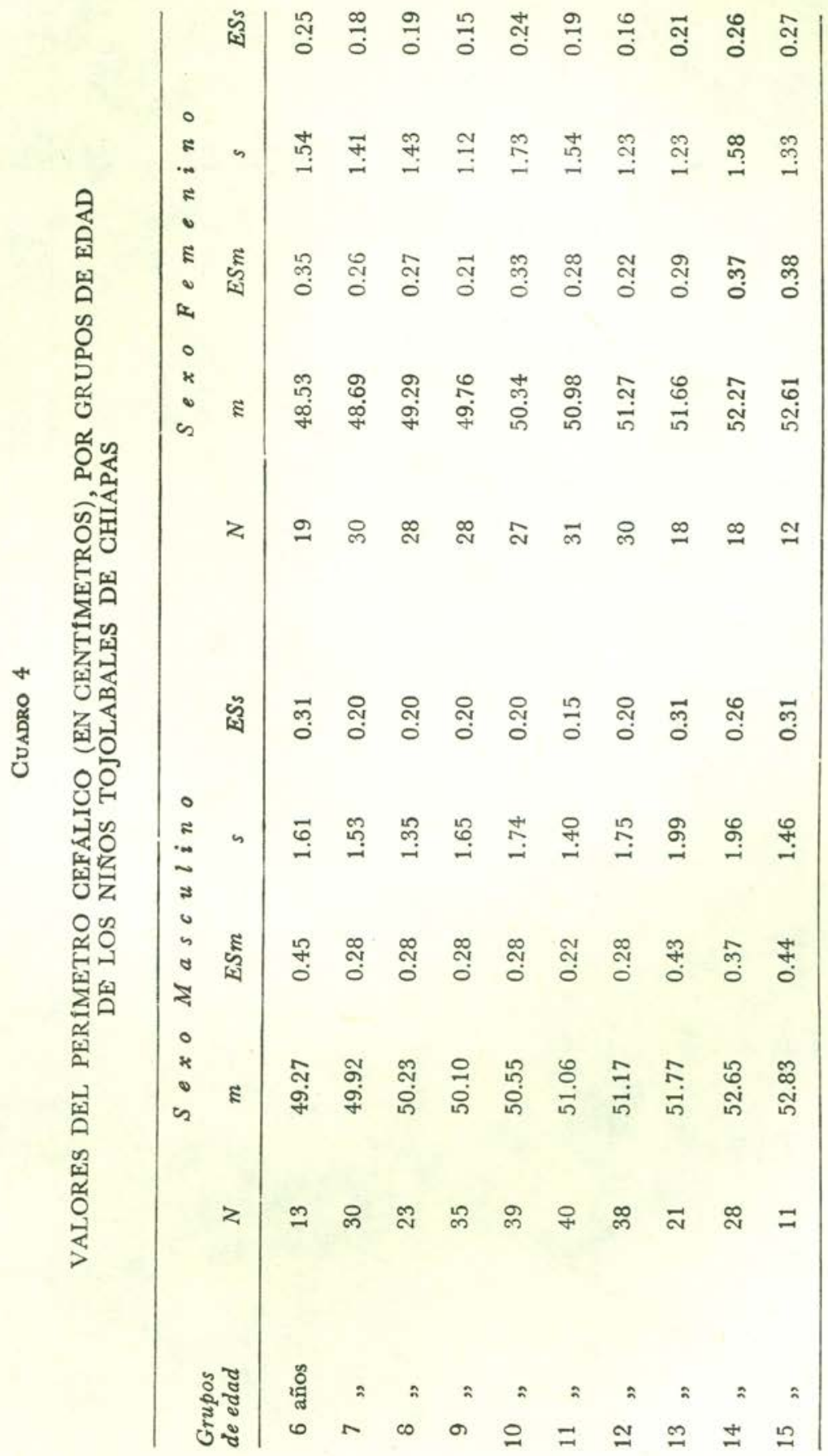

Estudios de Cultura Maya. Vol. XIII, 1981

Instituto de Investigaciones Filológicas/

Centro de Estudios Mayas, UNAM

http://www.iifilologicas.unam.mx/estculmaya/ 


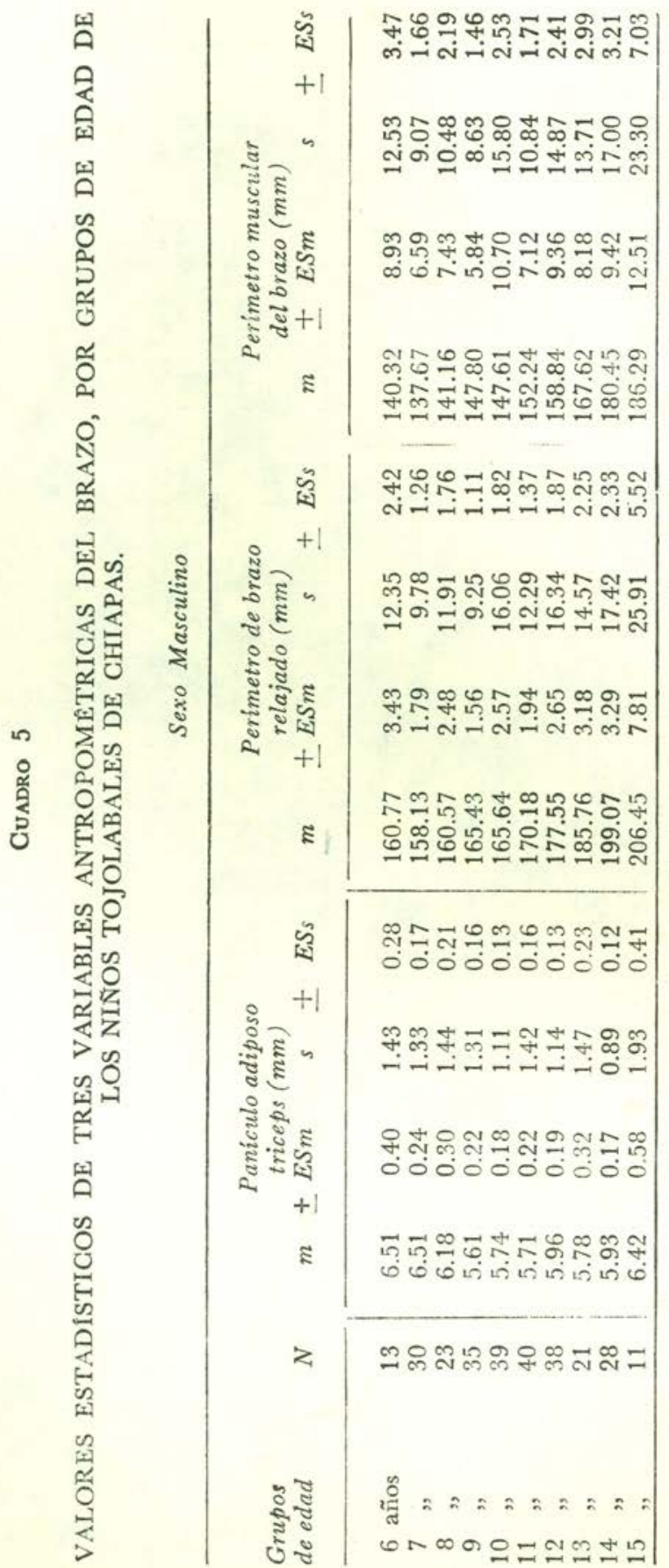

Estudios de Cultura Maya. Vol. XIII, 1981 Instituto de Investigaciones Filológicas/ Centro de Estudios Mayas, UNAM 


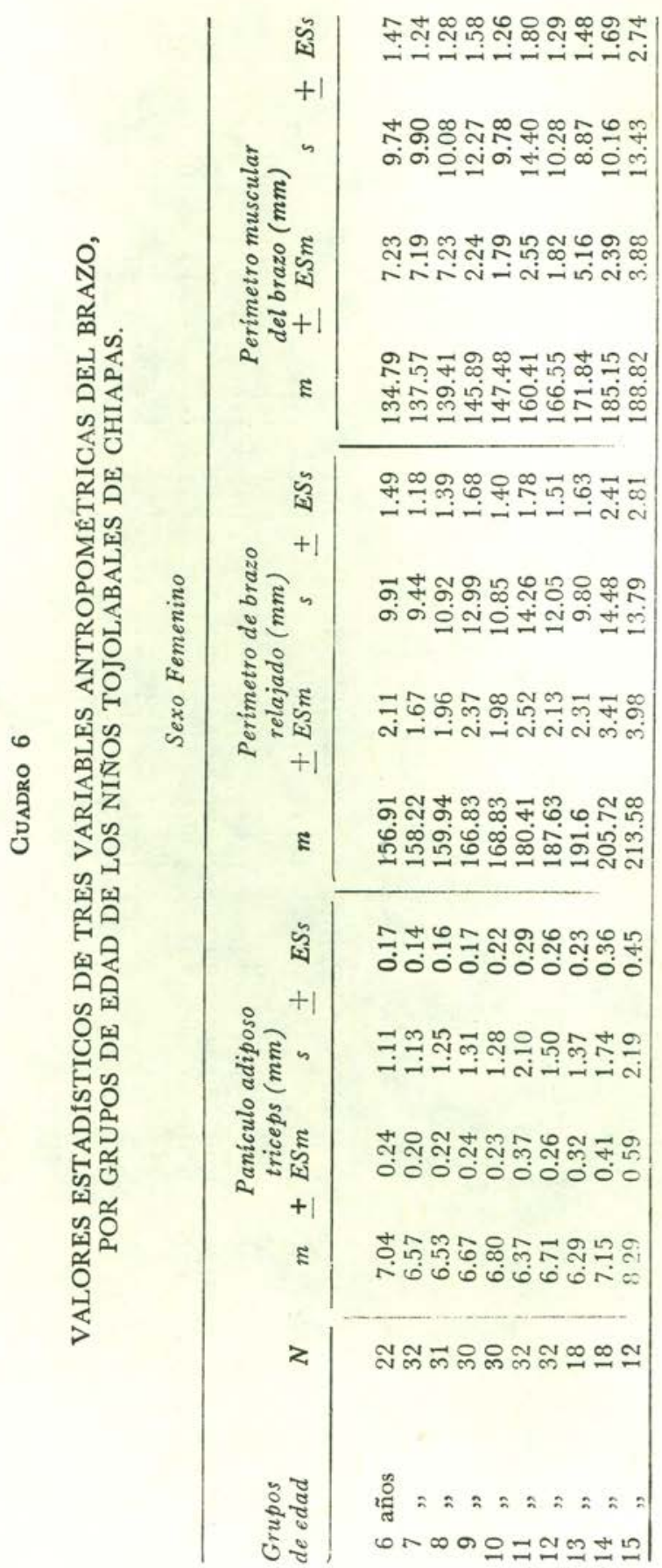




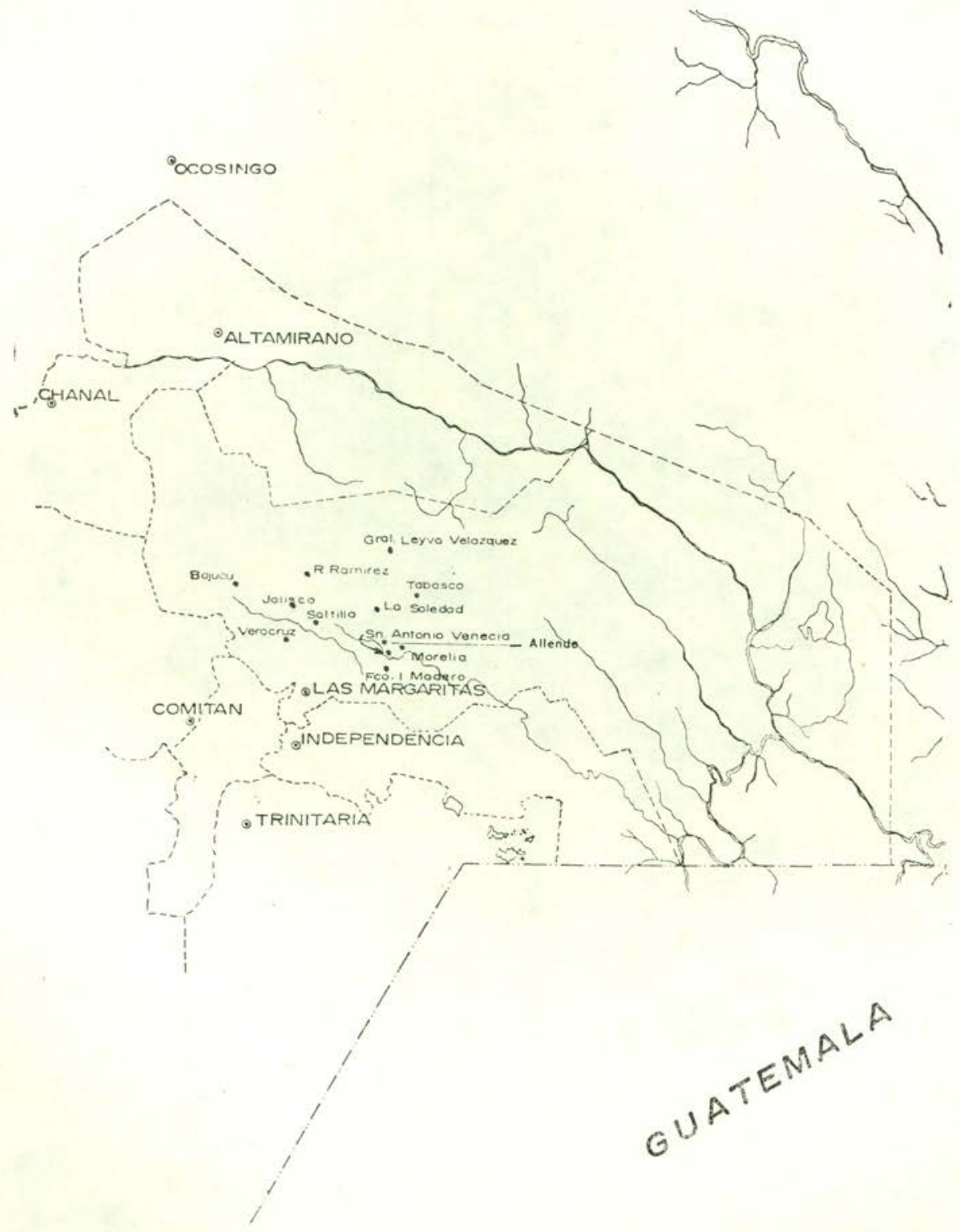

Municipio Las Margaritas, Edo. de Chiapas.

Estudios de Cultura Maya. Vol. XIII, 1981

Instituto de Investigaciones Filológicas/

Centro de Estudios Mayas, UNAM

http://www.iifilologicas.unam.mx/estculmaya/ 


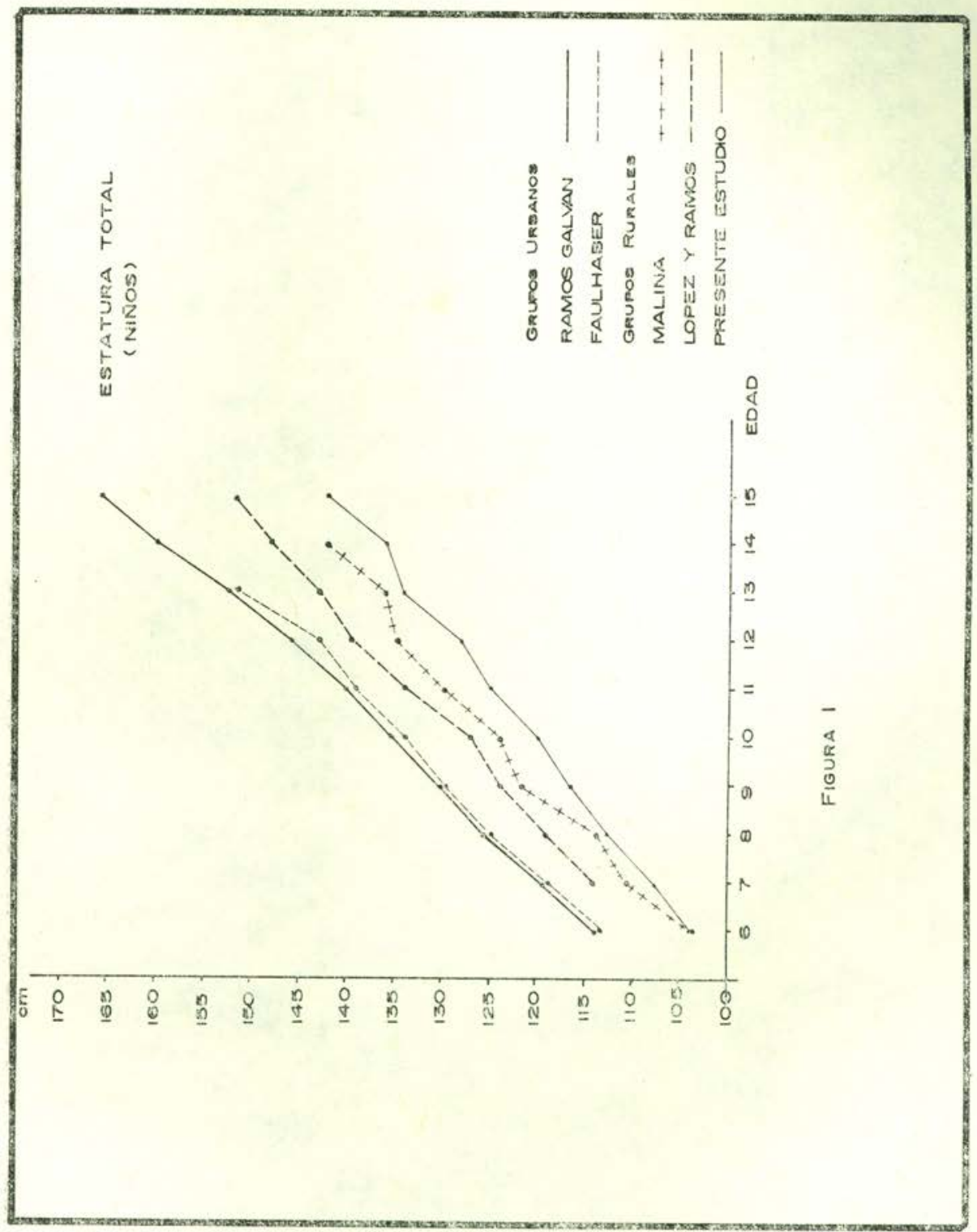

Estudios de Cultura Maya. Vol. XIII, 1981

Instituto de Investigaciones Filológicas/

Centro de Estudios Mayas, UNAM

http://www.iifilologicas.unam.mx/estculmaya/ 


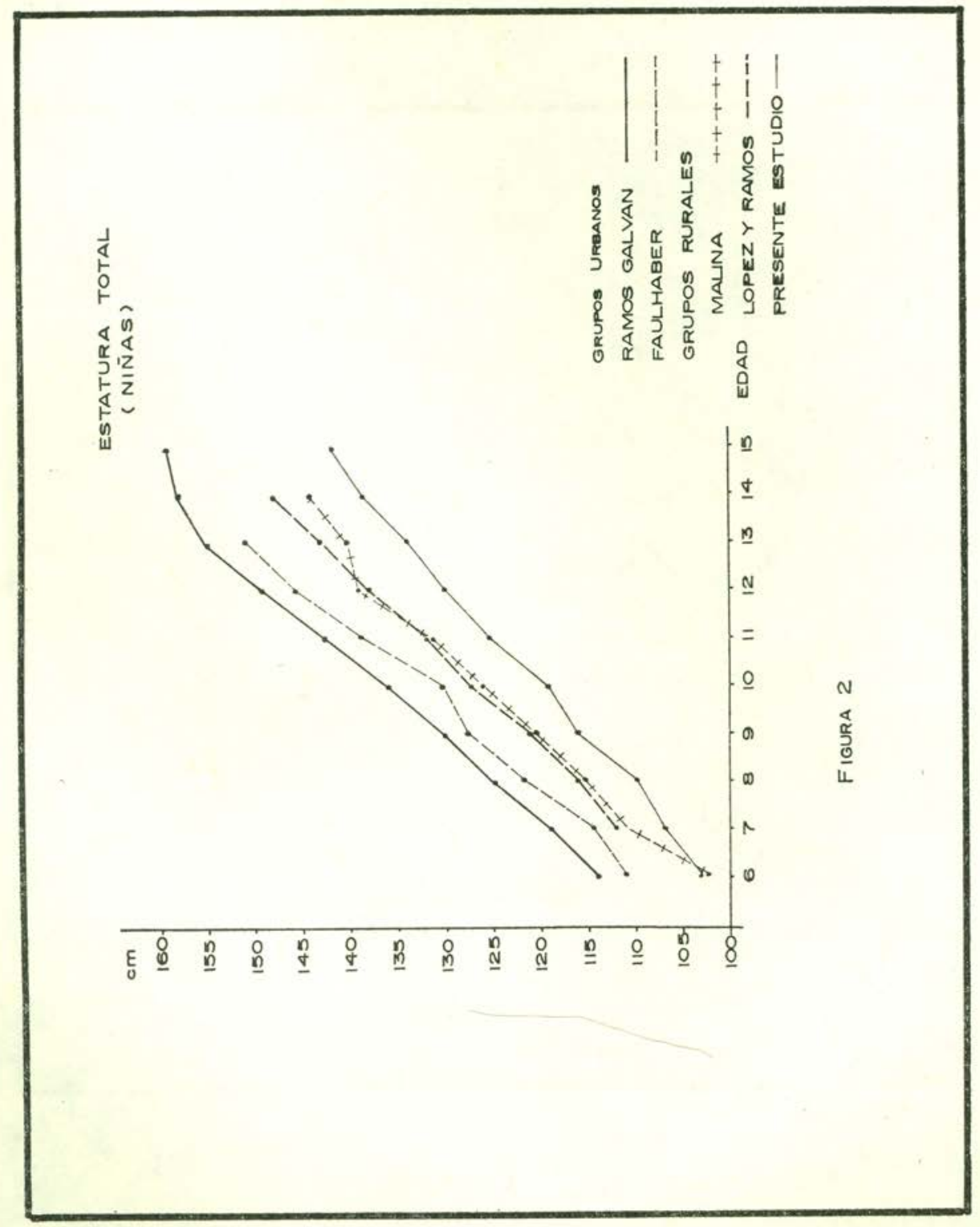

Estudios de Cultura Maya. Vol. XIII, 1981

Instituto de Investigaciones Filológicas/

Centro de Estudios Mayas, UNAM

http://www.iifilologicas.unam.mx/estculmaya/ 


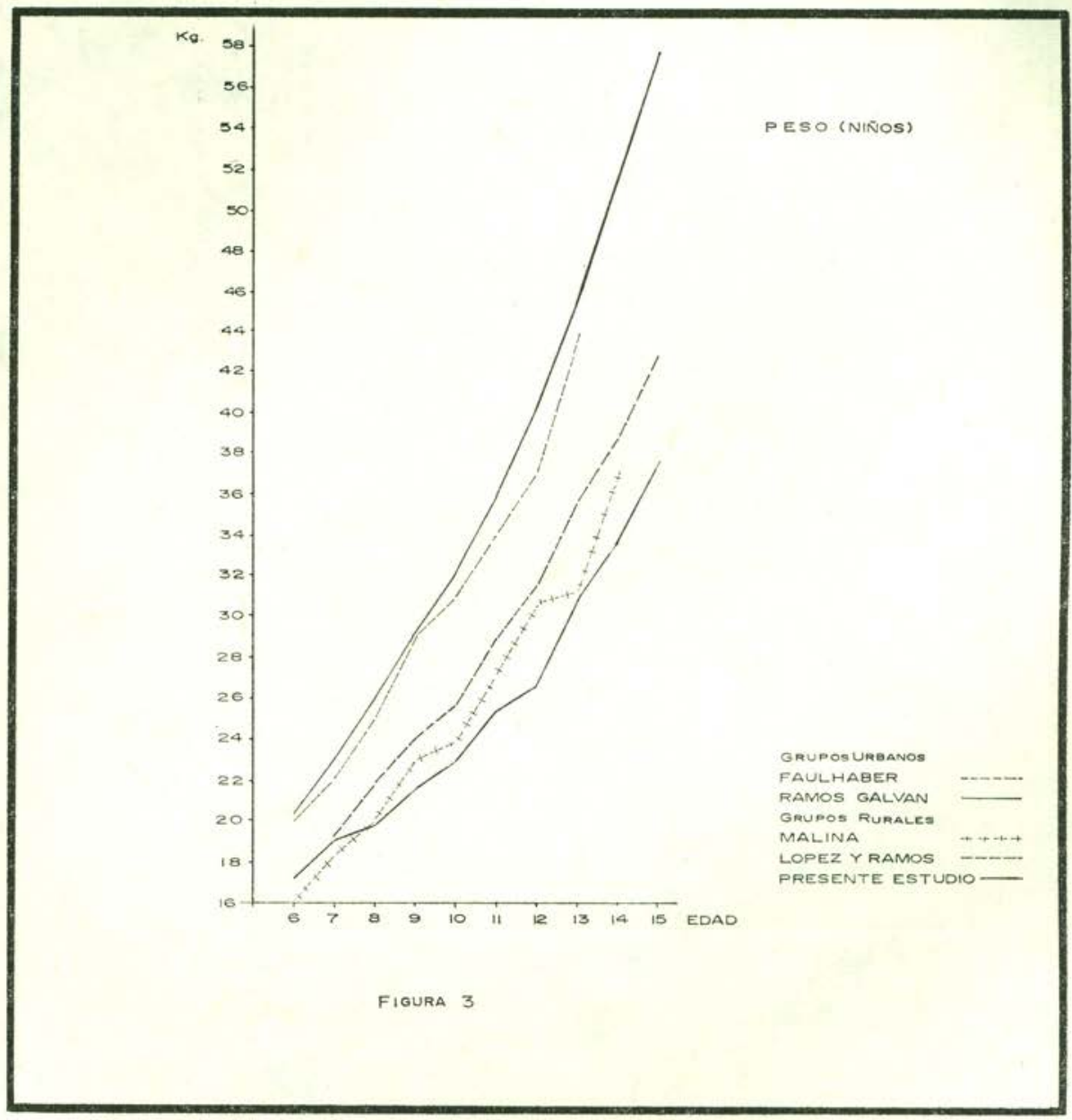

Estudios de Cultura Maya. Vol. XIII, 1981 Instituto de Investigaciones Filológicas/ Centro de Estudios Mayas, UNAM http://www.iifilologicas.unam.mx/estculmaya/ 


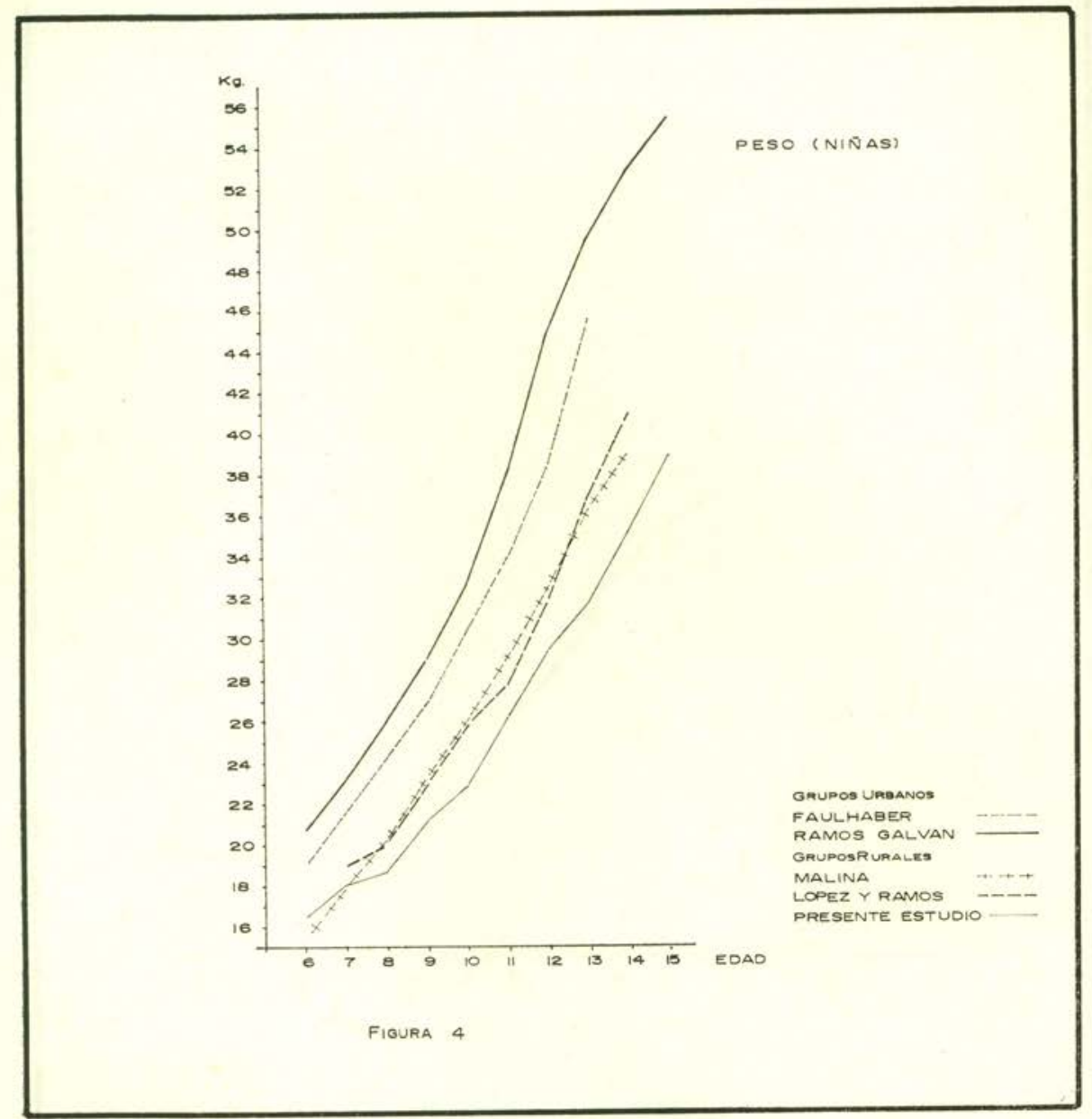

Estudios de Cultura Maya. Vol. XIII, 1981

Instituto de Investigaciones Filológicas/

Centro de Estudios Mayas, UNAM

http://www.iifilologicas.unam.mx/estculmaya/ 


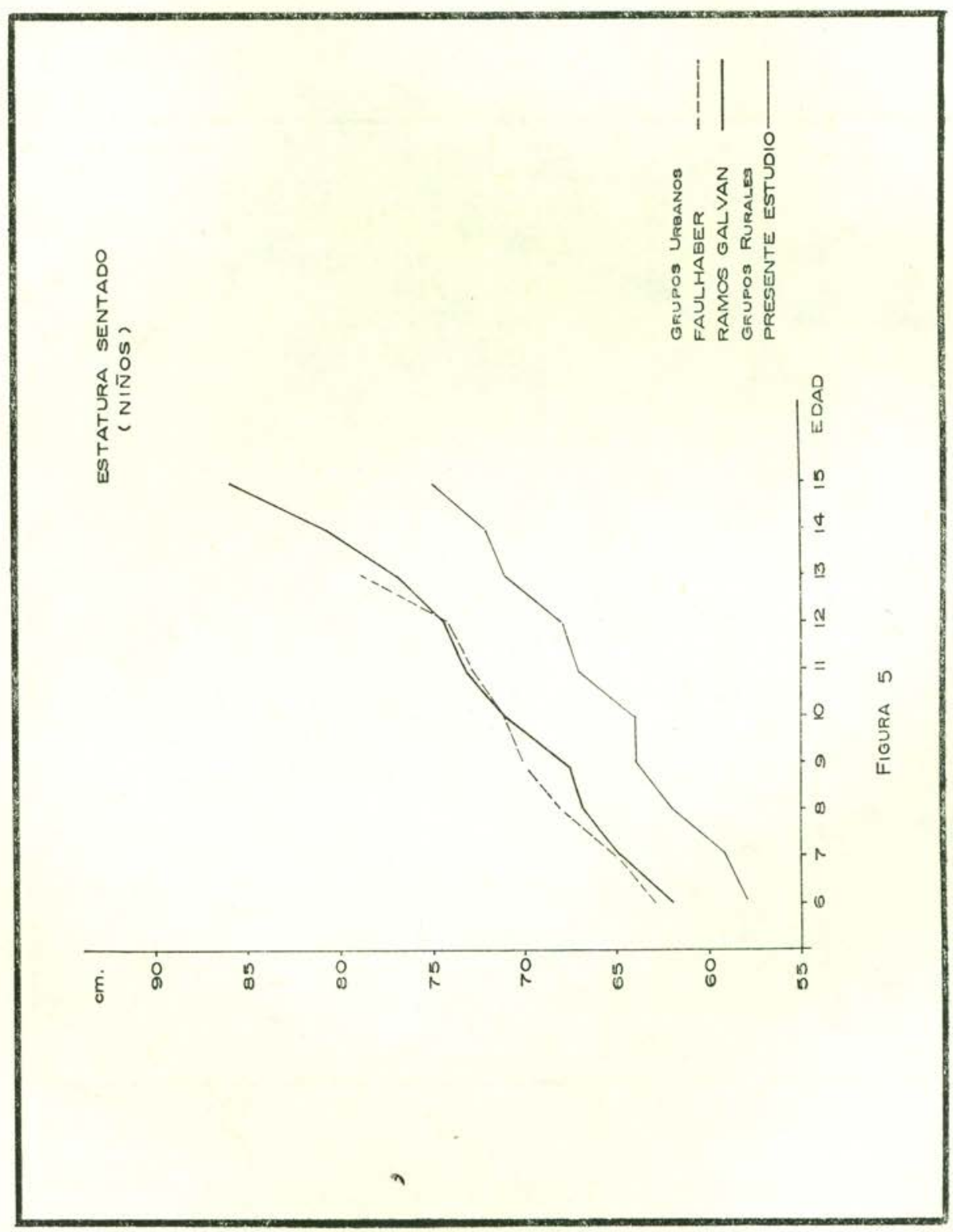

Estudios de Cultura Maya. Vol. XIII, 1981

Instituto de Investigaciones Filológicas/

Centro de Estudios Mayas, UNAM

http://www.iifilologicas.unam.mx/estculmaya/ 


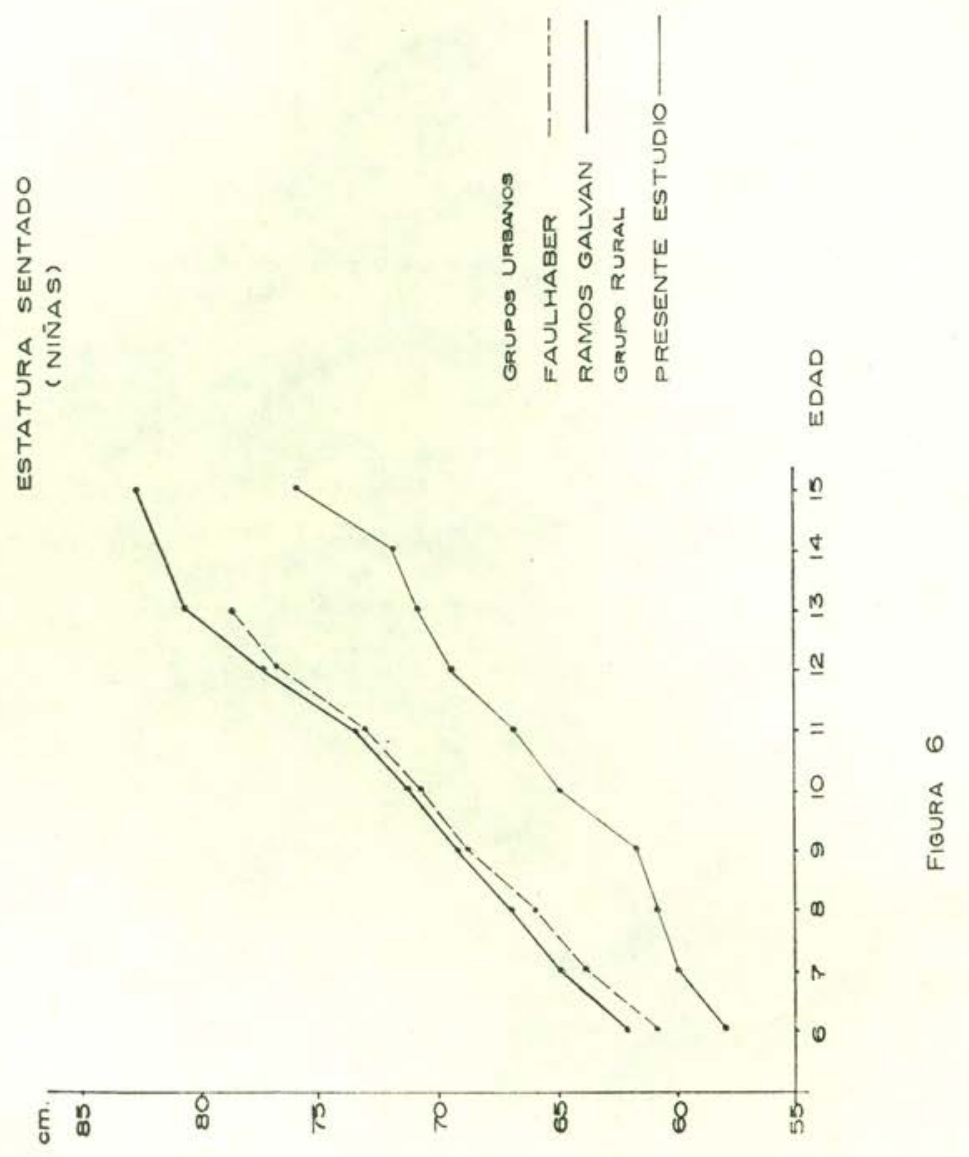




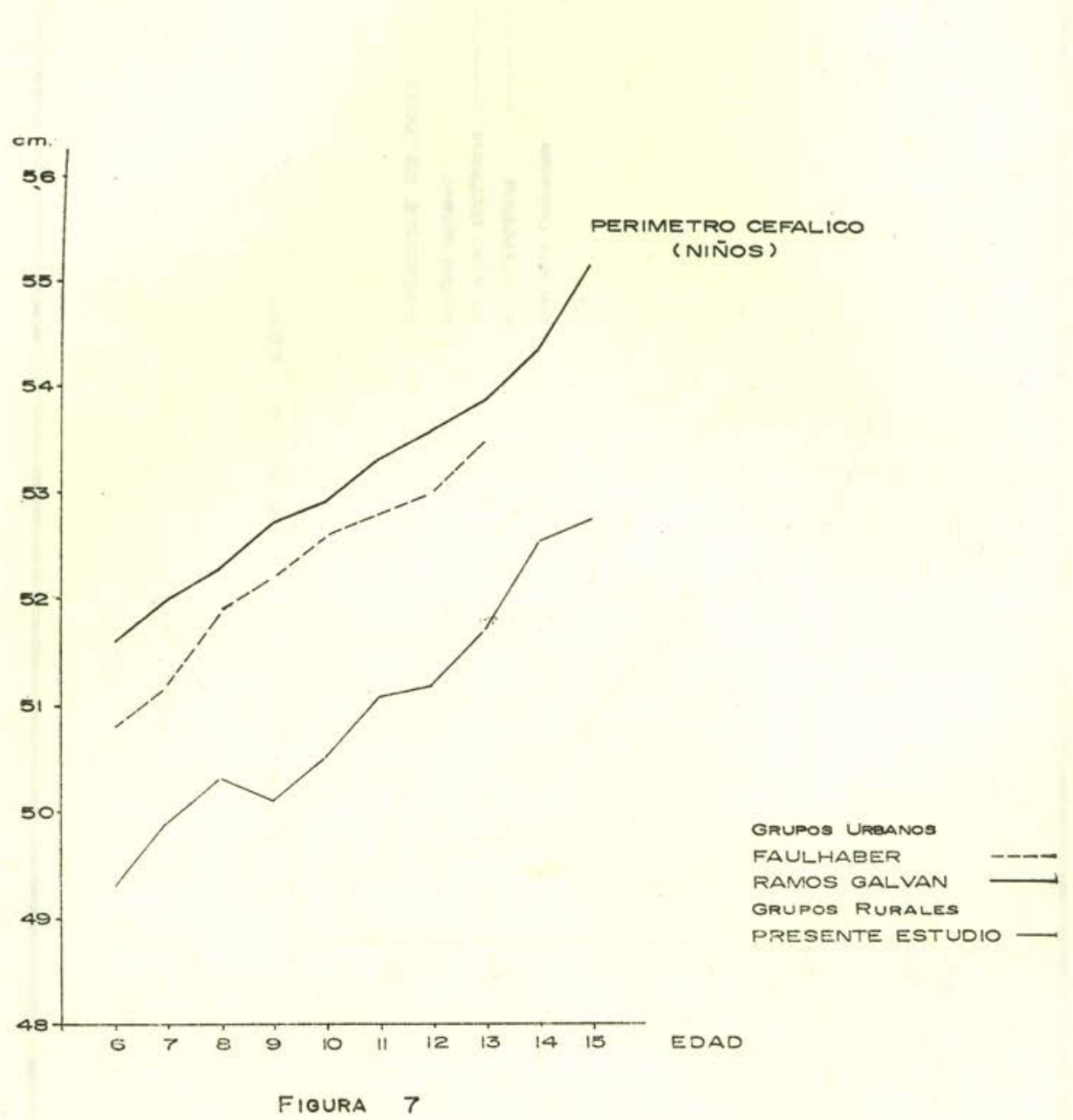

Estudios de Cultura Maya. Vol. XIII, 1981 Instituto de Investigaciones Filológicas/ Centro de Estudios Mayas, UNAM http://www.iifilologicas.unam.mx/estculmaya/ 


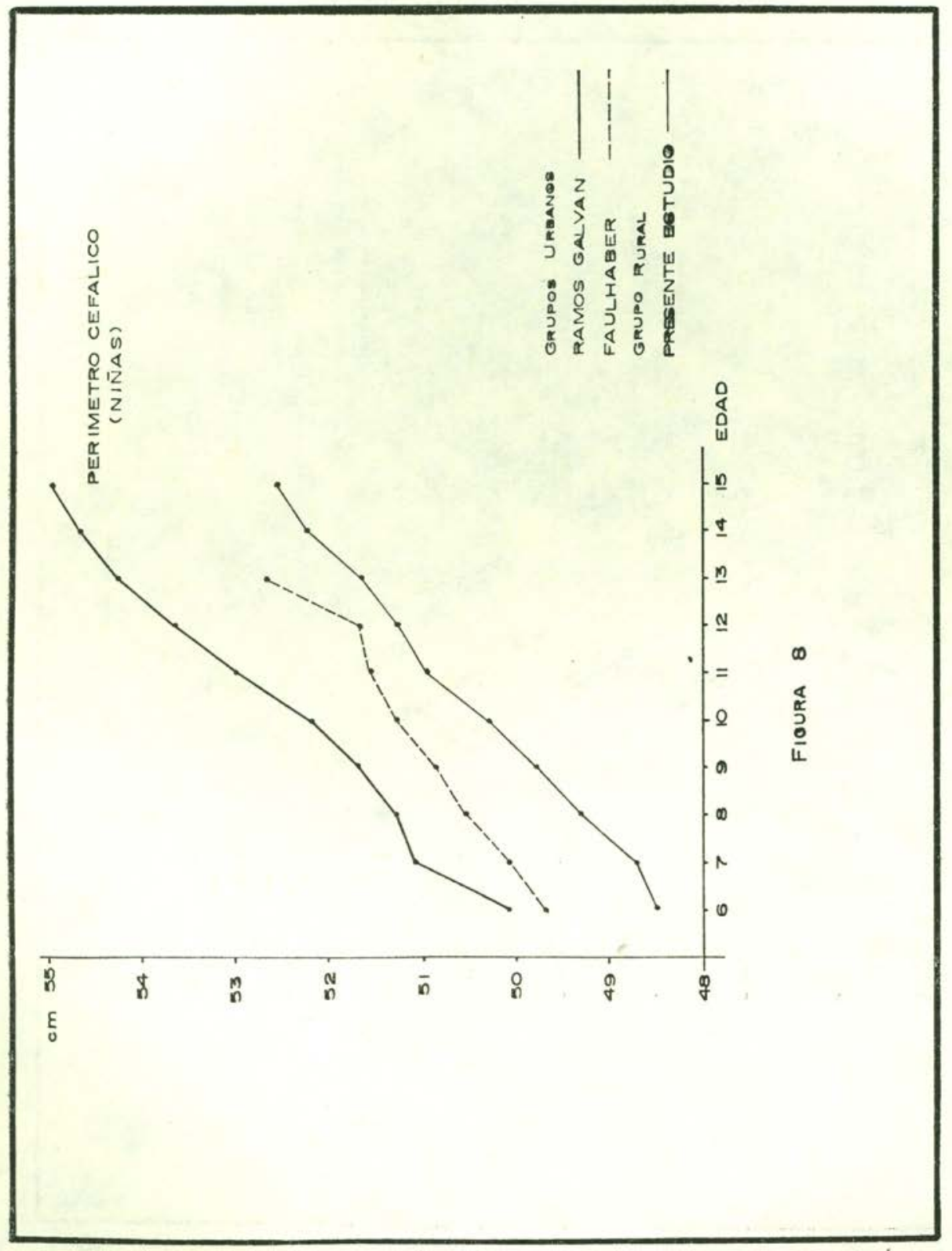

Estudios de Cultura Maya. Vol. XIII, 1981

Instituto de Investigaciones Filológicas/

Centro de Estudios Mayas, UNAM

http://www.iifilologicas.unam.mx/estculmaya/ 


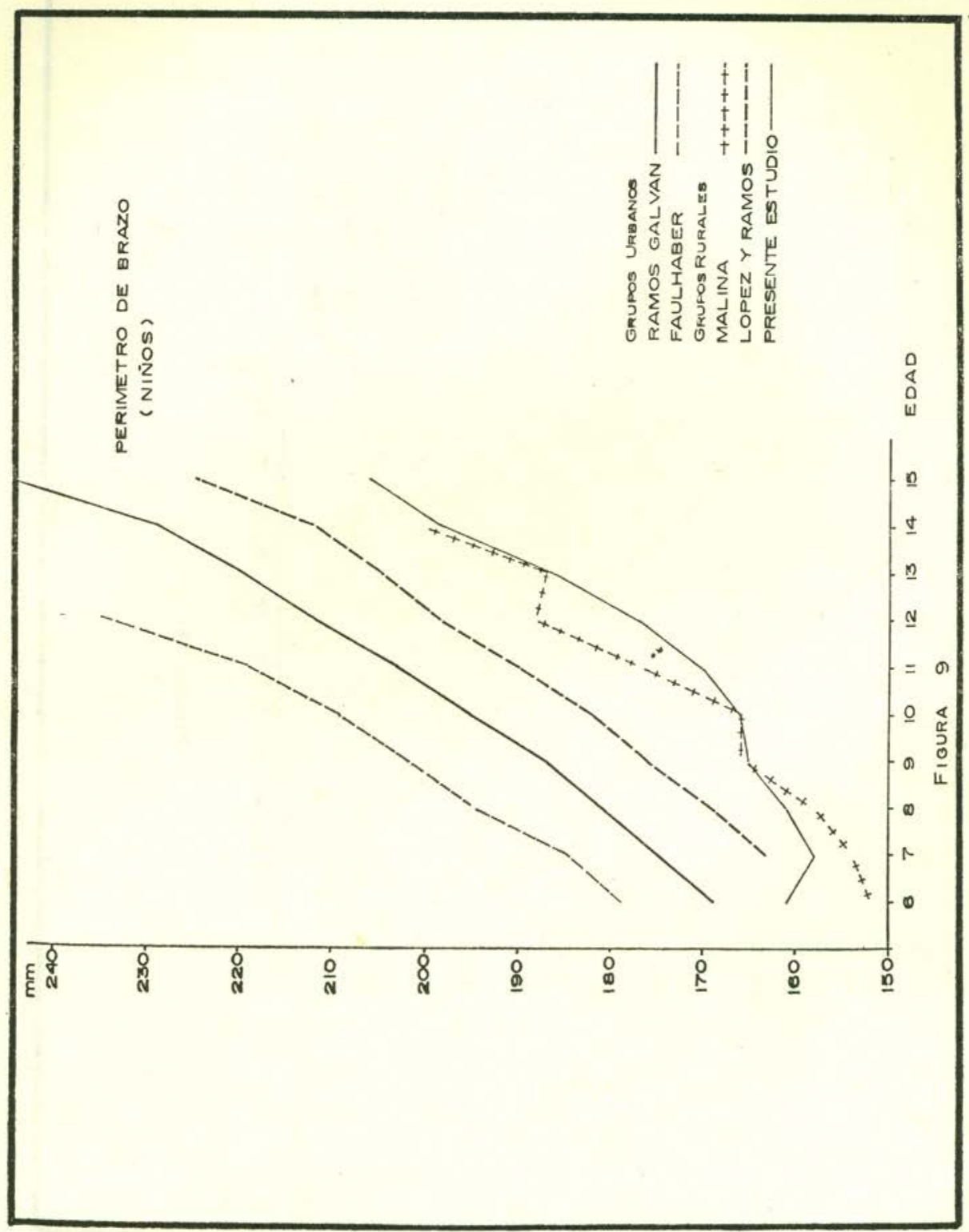




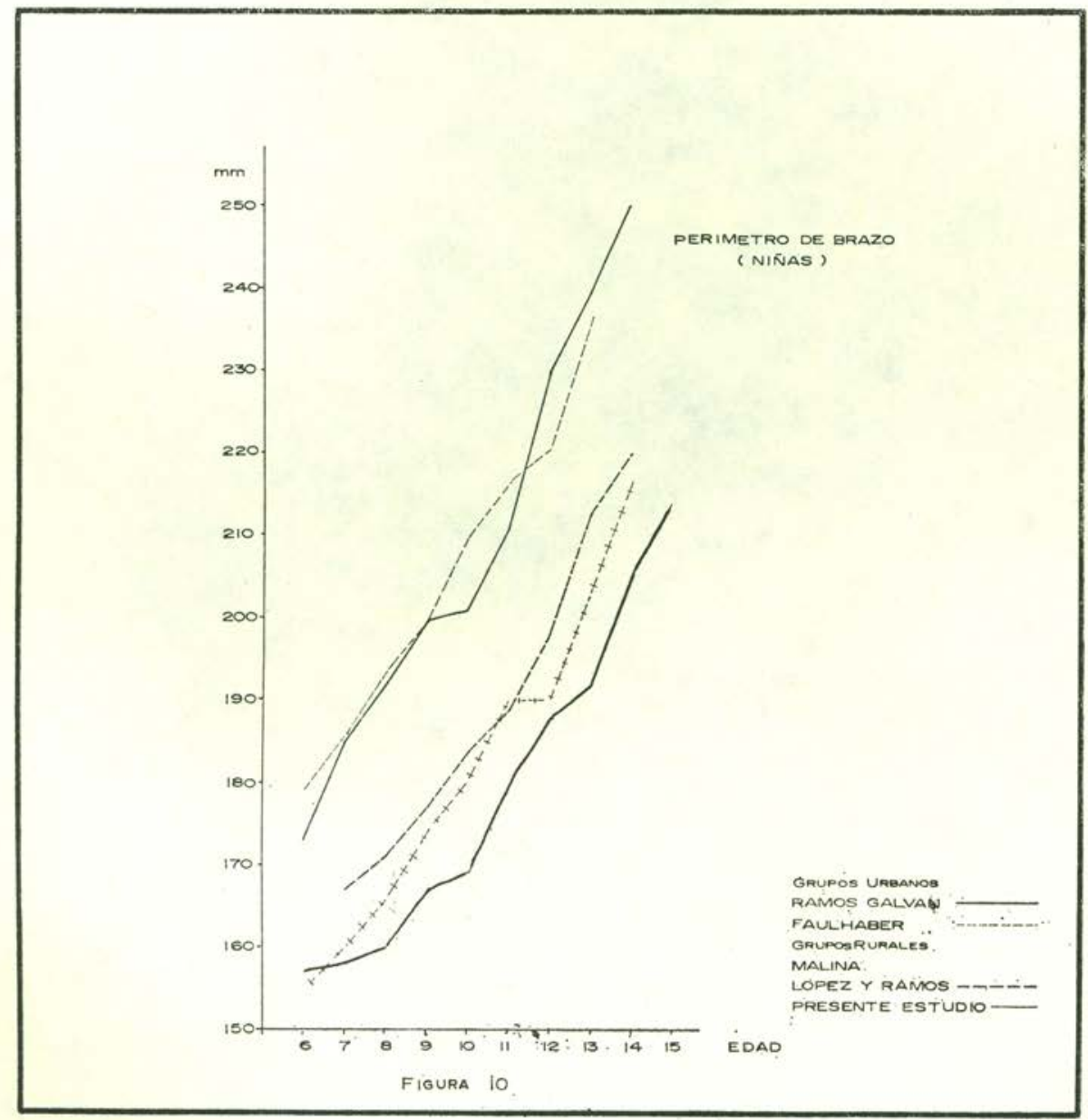

Estudios de Cultura Maya. Vol. XIII, 1981

Instituto de Investigaciones Filológicas/

Centro de Estudios Mayas, UNAM

http://www.iifilologicas.unam.mx/estculmaya/ 


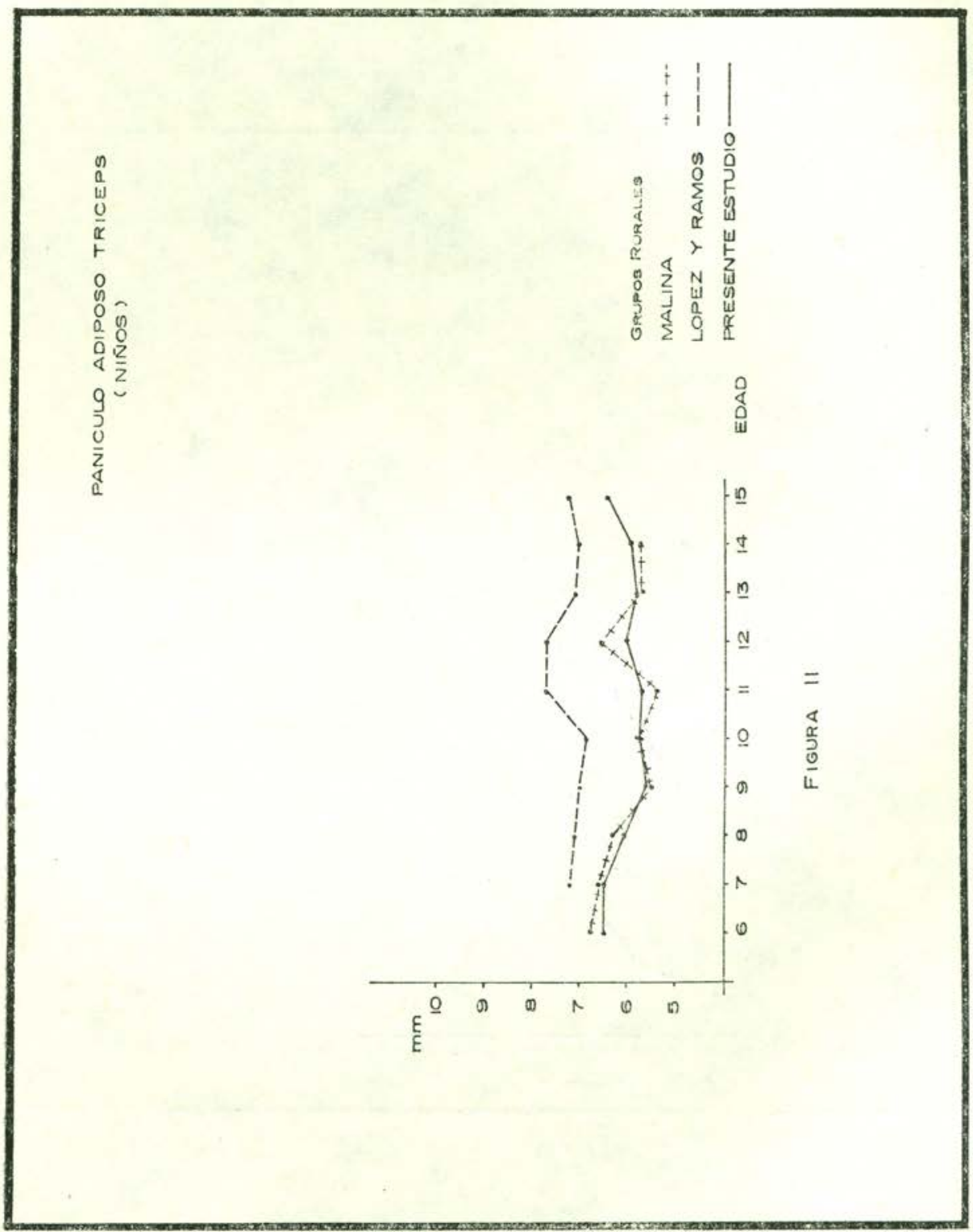

Estudios de Cultura Maya. Vol. XIII, 1981

Instituto de Investigaciones Filológicas/

Centro de Estudios Mayas, UNAM

http://www.iifilologicas.unam.mx/estculmaya/ 


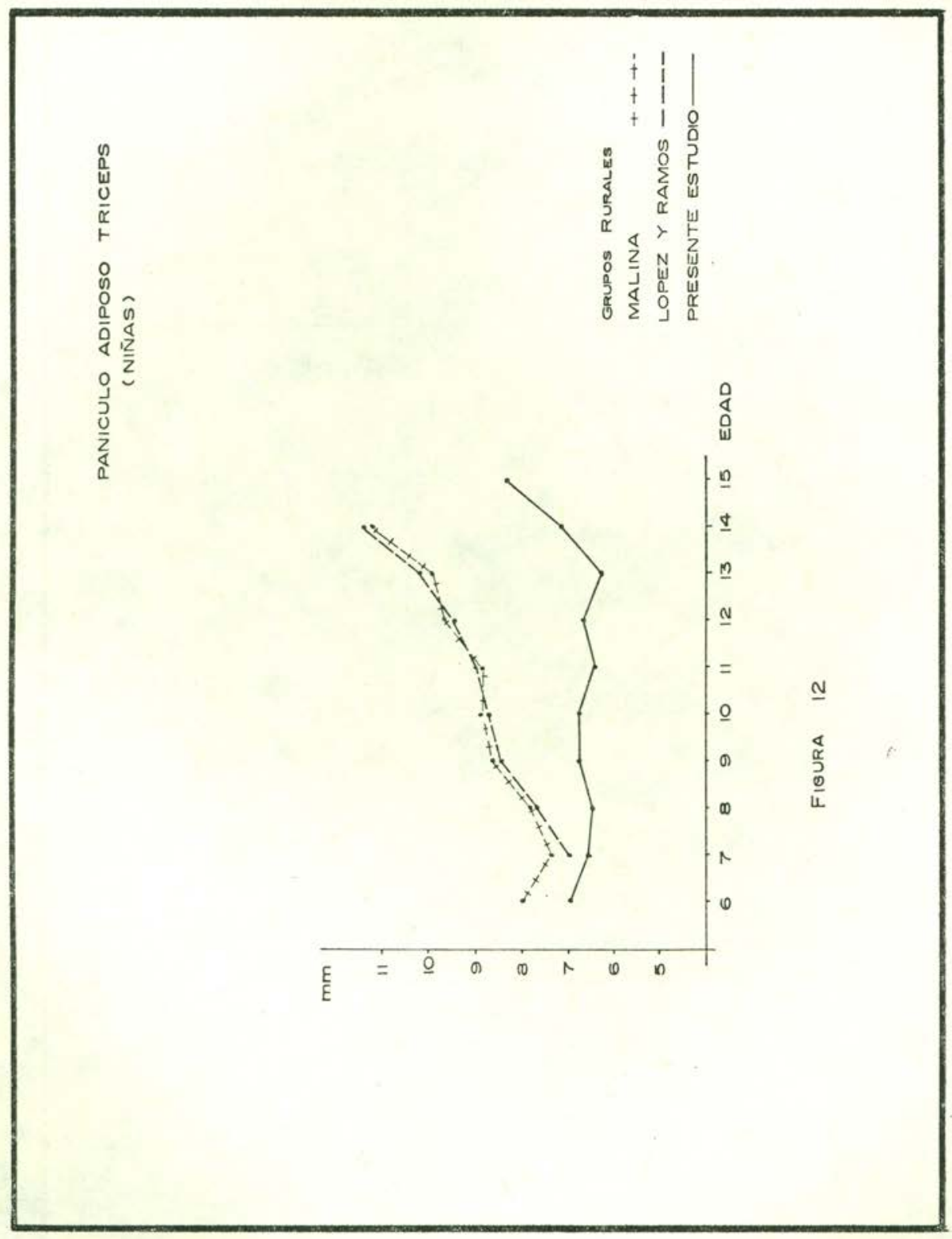

Estudios de Cultura Maya. Vol. XIII, 1981

Instituto de Investigaciones Filológicas/

Centro de Estudios Mayas, UNAM

http://www.iifilologicas.unam.mx/estculmaya/ 


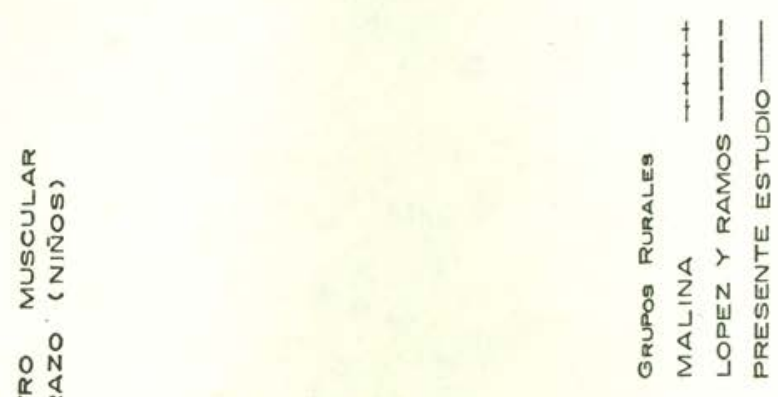

$\underset{r}{\mathbb{R}} \mathbb{x}$

紧

宸

号

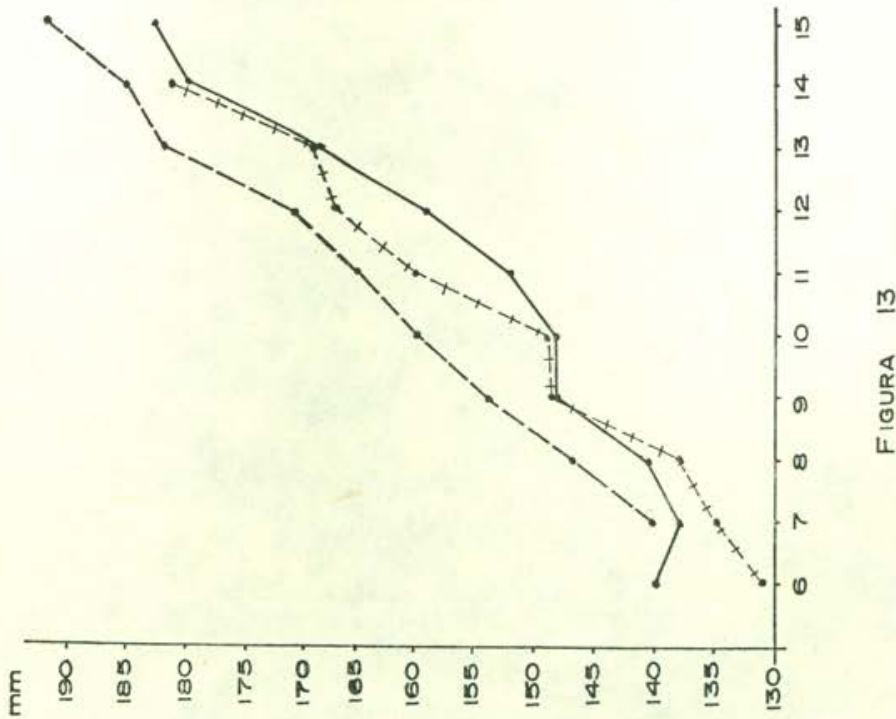




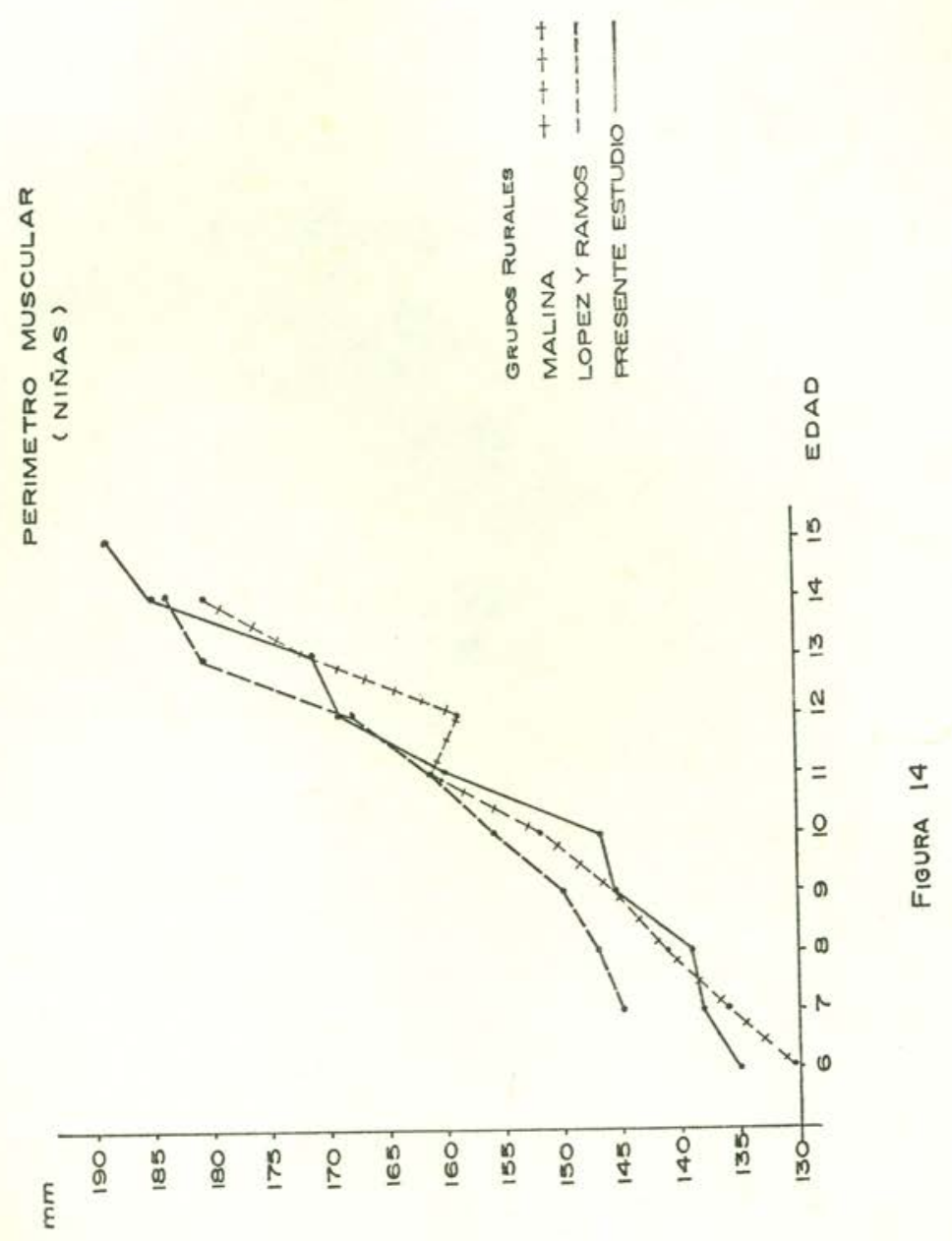

